\title{
Determination of Electricity Price in the Peak and Off Peak Times Separately for Each Season in Household Electricity Market of Iran
}

\author{
Kianoosh Ojand $^{1, *} \&$ Mohsen Nazari ${ }^{2}$ \\ ${ }^{1}$ Dept. of Management, University of Mehralborz, Tehran, Iran \\ ${ }^{2}$ School of Management, University of Tehran, Tehran, Iran \\ *Corresponding author: Dept. of Management, University of Mehralborz, No. 109, \\ Shokrollah St., Jal-e Al-e Ahmad Crossroad, N. Kargar Ave., Tehran, Iran. Tel: \\ 98-912-521-6041 E-mail: k.ojand@mehralborz.ac.ir
}

Received: October 28, 2013 Accepted: November 29, 2013 Published: December 16, 2013

doi:10.5296/rae.v5i4.4479ＵRL: http://dx.doi.org/10.5296/rae.v5i4.4479

\begin{abstract}
Electricity is a kind of goods or service which can't be store and economists calls it non storable and if it isn't consumed in the time it is generated it will be wasted. On the other side because of welfare and living level growth, using of electricity is increasing. Therefore it should be noted that investing on electricity always must be done to handle the growth of electricity consumption especially for handling electricity that is used in the peak load times. In this article it is tried to calculate the electricity price for household segment of electricity market with the help of peak load pricing method for each season in their peak load and off peak times. In this article it is tried to calculate electricity price for public utility service provider and private sector. Also it will be shown that with the current structure in Iran's electricity industry, why investing in electricity industry is not interesting for private sector.
\end{abstract}

Keywords: pricing; peak load pricing; electricity; peak load; demand function 


\section{Introduction}

In this section Theoretical Analysis, background of this study and goals of this research are explained.

\subsection{Theoretical Analysis}

Marketing mix is one of the basic concepts of marketing. In the field of marketing, first of all marketing strategies must be developed and then for implementing these strategies there is a need to use some kind of tools of marketing that are called marketing mix or 4P. Marketing mix are elements or tools that any organization can control them to satisfy its customers or use them for communicating with customers. Basic marketing mix is formed of four elements: Product, Promotion, Place and Price (Ekhlasi, Marketing principle, 2011).

In the field of marketing, price is one of the most flexible elements of marketing mix, because it can be changed in a short time by the supplier or provider of service or Product. On the other side, Price is the only marketing mix that makes income for the company. Generally there are two pricing policy in the world:

- $\quad$ Fixed price policy

- Dynamic price policy

In the fixed price policy, there is a fixed and unique price for all of the time periods and for all the customers.

In the dynamic price policy, prices can be changed for different segments of market according to the changes in the market situation. This issue specially can be seen in service sector. Electricity pricing must be dynamic and for the electricity it is suitable to separate the prices according to the peak load and off peak periods. By using this method, costs of electricity company somewhat can be compensated and customers may be encouraged to shift some part of their electricity consumption to the off peak periods (Ekhlasi, Service marketing, 2011).

There are different ways for pricing products and services. Some of these pricing methods are explained below.

Cost plus profit pricing method, that in this method summation of all production costs are calculated and some percentage of interest is add to it. Value base pricing is another way of determining the price of goods or services. In this method with the help of demand function and the customer demand for the product or service the price is assigned. Another way of pricing is competition based pricing which prices are based on the competitors' prices. There are other kinds of pricing for example pricing based on the market segmentation that prices are specified based on the market segmentation (Jeff Tanner, Mary Anne Raymond, 2010). For example electricity price in the tropical regions of Iran are cheaper than other region with good climate in Iran.

Another way of pricing that can be used for electricity is the Ramsey pricing. Theoretically if exclude people that don't pay for products or services that they use, then prices are good tools for coordinating supply and demand. Also it can be proved that if the first optimality 
condition in other sides of economy is established, marginal cost pricing can maximize the social welfare. It means that if in a place that market demand is provided and price is equal to marginal cost then social welfare which is consist of consumer surplus and production surplus is maximized (J.Pazhohan, T.Mohammadi, 2001).

Another way of pricing that is also used in this article for pricing the electricity is peak load pricing. This method of pricing is suitable for services that have non uniform demand and their demand is distributed non-uniformly in time periods. An obvious example for this method can be electricity, because in different hours of day and night it has different demands for the city of Tehran. In this case demand of household electricity in Tehran reaches its peak load in the time period between $6 \mathrm{pm}$ and 11pm and because of growth in consumption of electricity by new electric devices which are bought by the electricity consumers and building of new houses it is necessary to invest on generating more electricity for responding the peak load times.

Non storability specification of services especially electricity and cyclical fluctuations in demand makes peak load pricing mechanism beneficial both economically and socially. If fixed prices being use for all the season of a year then amount of demand will vary by the season changes. For covering peak load demand it is necessary to install new property and equipment, these equipment may be unused in off peak times and because these equipment are unused in off peak times and are expensive then inefficiency is the result of not being used in off peak times. Therefore to resolve this problem, peak load pricing method can handle this inefficiency by reducing prices in off peak times that leads to decrease in unused capacity (shy, 2008).

\subsection{Background}

Vilhelm Horn af Rantz and Anna Syren in their research which was done in the year 2010 in the city of Stockholm had researched on public transport pricing. In this research first of all with the help of comparative Studies they found effective factors of demand function and then they have found demand functions of peak load and off peak periods. It should be noted that in estimating demand function, availability of data is very important and factors that have available data must be considered. At the end with the help of estimated demand functions and Ramsey pricing they have discussed about subway ticket prices in public transport. By considering the results of their research and different situation that they have used for regression, results shows that on the average prices in the peak load times must be 50 percentage more that prices in the off peak times (Vilhelm Horn af Rantzien, Anna Syrén, 2010).

Karen Herter in his research which was done in the year 2007 in the California had studied effect of peak load pricing on the consumption of households with various kinds of income. Results of this research shows that customers that uses more electricity in kilowatt have more reduction in using electricity in comparison with customers that uses less electricity. But customers with less usage of electricity had more saving than other group in the electricity bills. This issue challenges the strategy of targeting customers with high consumption. Results shows that peak load pricing strategy is suitable for the time that all segment of 
market and electricity users are included. This research shows that electricity consumers with annual incomes of less than 50000 dollars had electricity bill growth of 5 to 10 percentage and for implementing new pricing strategies can be a good choice (Herter, 2007).

Karen Herter and Seth Wayland in their research which was done in the year 2010 in the California have analyzed data of 483 households in their peak load pricing study. In this study households has been divided in to 12 segmentation and average of peak load of electricity was studied for each of this segments according to weather and type of houses. Results shows that, customers with bigger houses, according to the consumption by the period and consumption by the percentage, respond to the peak load pricing more than other customers. Customers in the cold regions have the most reaction to the pricing according to the performance and percentage of usage. In this study is shown that household consumers will not have good reaction to the prices more than 0.5 dollars and 0.68 dollars per kilowatt hour (Karen Herter, Seth Wayland, 2010).

Seth Wayland and GR New sham in their study in the year 2010 in the America have surveyed pricing strategies for shifting peak load consumption to the off peak times or omitting some part of consumption of electricity in peak load times. In this study it is noted that demand of electricity consumption will increase in northern America and the challenge is using electricity equipment in a way to maximize the efficiency to handle that situation. Results of this study shows that best model of pricing is the critical peak load pricing strategy. Critical peak load pricing with the help of technology makes it possible to omit extra loads from the network. Evidence shows that this method makes some problems for the citizens. In the case of this study $30 \%$ reduction of consumption in peak load was estimated. By focusing on and supporting domestic sector without help of technology this amount of reduction can be reached. Other programs of normal consumption can make only $5 \%$ reduction in electricity usage (GR Newsham, BG Bowker, 2010).

Luca Coslovich in his study in the year 2008 in the Italy challenged the problems an electricity distributor faces when wants to determine electricity price. Solutions that are introduced in this article make the customer to shift their electricity consumption time by giving them(customers) enough motivation and this is possible when there is suitable diversity in prices. In this article electricity production system is divided in to 3 parts of production, transmission and distribution and it is mentioned that there is more competition in distribution sector (it must be considered that the case of this study is the Italy and the electricity is sold in a competitive market.). In this study it was tried to analyze opportunities that a distributor of electricity has, in order to maximize its profit and offer better prices to customers with the help of a mathematical model. From an electricity distributor point of view purpose of this study is to define prices changes in a way to motivate customer to shift their electricity consumption to the time periods that there isn't any lack of electricity. By using this method for distributor costs of buying electricity from the market will decrease and can have more profit and also customers will use benefits of lower prices (Coslovich, 2008).

\subsection{Goals of this study}

Services are not storable and they have peak load times of usage. Hence service providers 
must invest to match peak load times demand and this investment have some problems, for example this investment is unused in off peak times or it is impossible to invest enough.

According to the above description, electricity is a kind of service which cannot be stored. This service has peak time services in 24 hours of a day and also electricity usage is increasing every day, relatively this increase in electricity consumption, increases electricity usage in peak load times. Hence it is needed to build new power plants, develop electricity networks and so on. Building new power plants and developing networks needs a great investment. For this reason the goal of this research is to find suitable electricity prices for the peak load and off peak times in a way to help decrease electricity consumption in the peak load times and also by keeping the social welfare high and maximize the electricity suppliers' profit. For calculating electricity price for each of peak load and off peak times which is the main goal of this research it is necessary to reach some secondary objectives that are listed below:

1. Defining conceptual model of demand function for each of peak load and off peak times

2. Estimating demand function for household consumer in peak load and off peak times

3. Determining electricity prices for each of them

\section{Household Peak Load Pricing}

In this section methodology and practical experiences that were used to calculate electricity prices of household sector of electricity market are explained.

\subsection{Methodology}

In this part whole process of electricity peak load pricing which was used will be explained. For answering the questions of this study, four steps must be taken. These steps are explained below:

\subsubsection{First step}

for calculating electricity price with the help of peak load pricing method it is needed to estimate electricity demand function, so for estimating the electricity demand function it is necessary to study researches related to estimating electricity demand functions and extract effective factors for demand function.

\subsubsection{Second step}

After extracting effective factors for demand function, data of these factors must be collected. It must be noted that only factors with available data are inserted in the conceptual model of the demand function and others are ignored. After checking the availability of data conceptual model of demand function is introduced.

\subsubsection{Third step}

In this step by the help of Econometric methods, the conceptual model of demand function 
and data demand functions for each of peak load times and off peak times are estimated.

\subsubsection{Forth step}

In this step two types of costs that are needed to calculate electricity prices with the help of peak load pricing are calculated. These two costs are operational cost and capacity cost.

\subsubsection{Final step}

In this step for answering other question of this research, it is needed to have elements that are listed below:

1. Demand functions which were estimated in the third stem

2. Costs of producing electricity for electricity supplier.

\subsection{Method of peak load pricing}

In this section, method of calculating electricity prices for public utility service provider and private sector are described.

\subsubsection{Peak load pricing method for public utility service provider}

In this session general formulation for calculating electricity price for the public utility service provider by the help of peak load pricing method is described. Suppose that these two demand functions exist.

$$
\begin{gathered}
p_{A}=\alpha_{A}-\beta_{A} q_{A} \\
p_{B}=\alpha_{B}-\beta_{B} q_{B}
\end{gathered}
$$

The regulated public utility's marginal capacity cost is $\mu_{k}$, the marginal operating cost is $\mu_{o}$ and there are no fixed costs, so $\varnothing=0 . D_{A}$ and $D_{B}$ are units of time related to the length of each period. A regulator who maximizes social welfare equates prices to the relevant marginal costs, so for the case in which season $\mathrm{A}$ is a peak season,

$$
\begin{gathered}
D_{A} p_{A}=D_{A}\left(\alpha_{A}-\beta_{A} q_{A}\right)=\mu_{k}+D_{A} \mu_{o} \\
D_{B} p_{B}=D_{B}\left(\alpha_{B}-\beta_{B} q_{B}\right)=D_{B} \mu_{o}
\end{gathered}
$$

Yielding

$$
q_{A}^{p l}=\frac{D_{A}\left(\alpha_{A}-\mu_{o}\right)-\mu_{k}}{D_{A} \beta_{A}} \text { and } q_{B}^{p l}=\frac{\alpha_{B}-\mu_{o}}{\beta_{b}}
$$

Clearly, at this stage it must be verified that season A is the peak season by checking whether $q_{B}^{p l} \leq q_{A}^{p l}$. Otherwise, one should check whether season B might be the peak season, or whether a shifting-peak case is encountered. Substituting (5) into the inverse demand functions obtains the prices set by a regulator when $\mathrm{A}$ is the peak season. Therefore,

$$
p_{A}^{p l}=\alpha_{A}-\beta_{A} q_{A}^{p l}=\mu_{o}+\frac{\mu_{k}}{D_{A}} \text { and } p_{B}^{p l}=\alpha_{B}-\beta_{B} q_{B}^{p l}=\mu_{o}
$$


Thus, the peak price should be equal to the marginal operating cost plus the cost of capacity divided by the duration of the peak season. The off peak season price should be equal to the marginal operation cost only, because some capacity remains idle.

Under the shifting peak case, the socially optimal investment in service capacity is determined by

$$
D_{A} p_{A}+D_{B} p_{B}=D_{A}\left(\alpha_{A}-\beta_{A} q_{A}\right)+D_{B}\left(\alpha_{B}-\beta_{B} q_{B}\right)=\mu_{k}+\left(D_{A}+D_{B}\right) \mu_{o}
$$

Observe again that the marginal operating cost on the right-hand side of (7) is multiplied by the duration of one full cycle, which is equal to $D_{A}+D_{B}$. Therefore,

$$
q_{A}^{p l}=q_{B}^{p l}=\frac{D_{A}\left(\alpha_{A}-\mu_{o}\right)+D_{B}\left(\alpha_{B}-\mu_{o}\right)-\mu_{k}}{D_{A} \beta_{A}+D_{B} \beta_{B}}
$$

Comparing (8) with (5) reveals again that in a shifting peak case, the duration of all seasons influences the determination of the profit maximizing capacity level (rather than the duration of the peak season only). Substituting (8) in to the inverse demand functions yields the socially optimal price in each season:

$$
\begin{gathered}
p_{A}^{p l}=\frac{\beta_{A} \mu_{k}+\beta_{A} \mu_{o}\left(D_{A}+D_{B}\right)+D_{B}\left(\alpha_{A} \beta_{B}-\alpha_{B} \beta_{A}\right)}{D_{A} \beta_{A}+D_{B} \beta_{B}} \\
p_{B}^{p l}=\frac{\beta_{B} \mu_{k}+\beta_{B} \mu_{o}\left(D_{A}+D_{B}\right)+D_{A}\left(\alpha_{B} \beta_{A}-\alpha_{A} \beta_{B}\right)}{D_{A} \beta_{A}+D_{B} \beta_{B}}
\end{gathered}
$$

It must be noted that shifting peak load is not used in this study (shy, 2008).

\subsubsection{Peak load pricing method for private sector}

Suppose that one cycle consist of two seasons labeled A and B. the duration of season A and B are $D_{A}$ and $D_{B}$ units of time, respectively. $q_{A}$ and $q_{b}$ denote the demand for the service per unit of time during seasons $A$ and $B$, respectively. The prices for the service (per service unit, per unit of time) are denoted by $p_{A}$ and $p_{B}$. Linear demand functions are assumed so that $p_{A}=\alpha_{A}-\beta_{A} q_{A}$ and $p_{B}=\alpha_{B}-\beta_{B} q_{B}$, where $\alpha_{A}, \alpha_{B}, \beta_{A}$ and $\beta_{B}$ are all strictly positive parameters.

If season $\mathrm{A}$ is a peak season, the seller should solve

$$
\begin{gathered}
M R(q) \frac{d x(q)}{d q}=\frac{d[p(q) q]}{d q}=\alpha-2 \beta q \rightarrow M R_{A}=\alpha_{A}-2 \beta_{A} q_{A} \text { and } M R_{B}=\alpha_{B}-2 \beta_{B} q_{B} \\
D_{A} M R_{A}=D_{A}\left(\alpha_{A}-2 \beta_{A} q_{A}\right)=\mu_{k}+D_{A} \mu_{o} \\
D_{B} M R_{B}=D_{B}\left(\alpha_{B}-2 \beta_{B} q_{B}\right)=D_{B} \mu_{o}
\end{gathered}
$$

Yielding

$$
q_{A}^{p l}=\frac{D_{A}\left(\alpha_{A}-\mu_{o}\right)-\mu_{k}}{2 D_{A} \beta_{A}} \text { and } q_{B}^{p l}=\frac{\alpha_{B}-\mu_{o}}{2 \beta_{b}}
$$

Clearly, it must be verified at this stage that season A is the peak season by checking whether 
$q_{B}^{p l} \leq q_{A}^{p l}$. Otherwise, one should check wether season B might be the peak season, or whether a shifting-peak case is encountered. At this stage, one can also investigate how demand in each season is affected by extending the duration of the season. More precisely, (14) implies that

$$
\frac{d q_{A}^{p l}}{d D_{A}}=\frac{\mu_{k}}{2 \beta_{A} D_{A}^{2}}>0 \text { and } \frac{d q_{B}^{p l}}{d D_{A}}=0
$$

Thus, an increase in the duration of the peak season results in a higher investment in service capacity, and hence in the flow of service provided during the peak season. In contrast, the off peak service flow is invariant with respect to changes in the duration of seasons. This is because at each point in the time during the off peak season, consumers are charged proportionally to the flow of marginal operating cost only. In contrast, prolonging the peak season implies that the cost of capacity is speared over a longer period of time, which permits a higher investment in capacity. To conclude the general formulation for private sector, the prices are computed by

$$
\begin{aligned}
& p_{A}^{p l}=\alpha_{A}-\beta_{A} q_{A}^{p l}=\frac{D_{A}\left(\alpha_{A}+\mu_{o}\right)+\mu_{k}}{2 D_{A}} \\
& p_{B}^{p l}=\alpha_{B}-\beta_{B} q_{B}^{p l}=\frac{\left(\alpha_{B}+\mu_{o}\right)}{2}
\end{aligned}
$$

Shifting peak case is not explained here (shy, 2008).

\subsubsection{Determining demand functions}

For calculating electricity price by the use of peak load pricing method it is needed to estimate demand functions of peak load and off peak periods for household electricity consumers. In this study as it was described in the "section 2.1. 2.1 Methodology" the three first step of methodology are related to estimation of demand functions.

\subsubsection{First step or extracting effective factors}

In the first step by the help of comparative Studies primary effective factors of electricity demand functions are extracted. These factors are shown in the table 1. 
Table 1: Primary effective factors

\begin{tabular}{|c|c|}
\hline \multirow{10}{*}{ 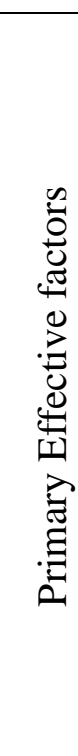 } & 1.electricity price \\
\hline & 2.family income \\
\hline & 3.Average electricity consumption in a month \\
\hline & 4.Economic restructuring and political instability and war \\
\hline & 5.Weather conditions \\
\hline & 6.Size of home \\
\hline & 7.The price of alternative energy (e.g. gas, oil, etc.) \\
\hline & 8.The average price of other goods \\
\hline & 9.Number of household Subscribers \\
\hline & 10.population \\
\hline
\end{tabular}

Factors that are shown in the table 1 are only primary effective factors for demand functions. Final effective factors are extracted from these factors by the availability of data.

\subsubsection{Second step or generating conceptual models}

In the second step existence of data for these factors was checked and according to the availability of data, it was decided to defined variables in the table 2 as variables of conceptual model of electricity demand functions in the Tehran city.

All of the data that are used in this study were gathered from governmental organization such as Great Tehran electricity distribution company, Center of statistics, Meteorology Organization and central bank of Islamic Republic of Iran. All the data are defined monthly.

Table 2: Variables of conceptual model of electricity demand function

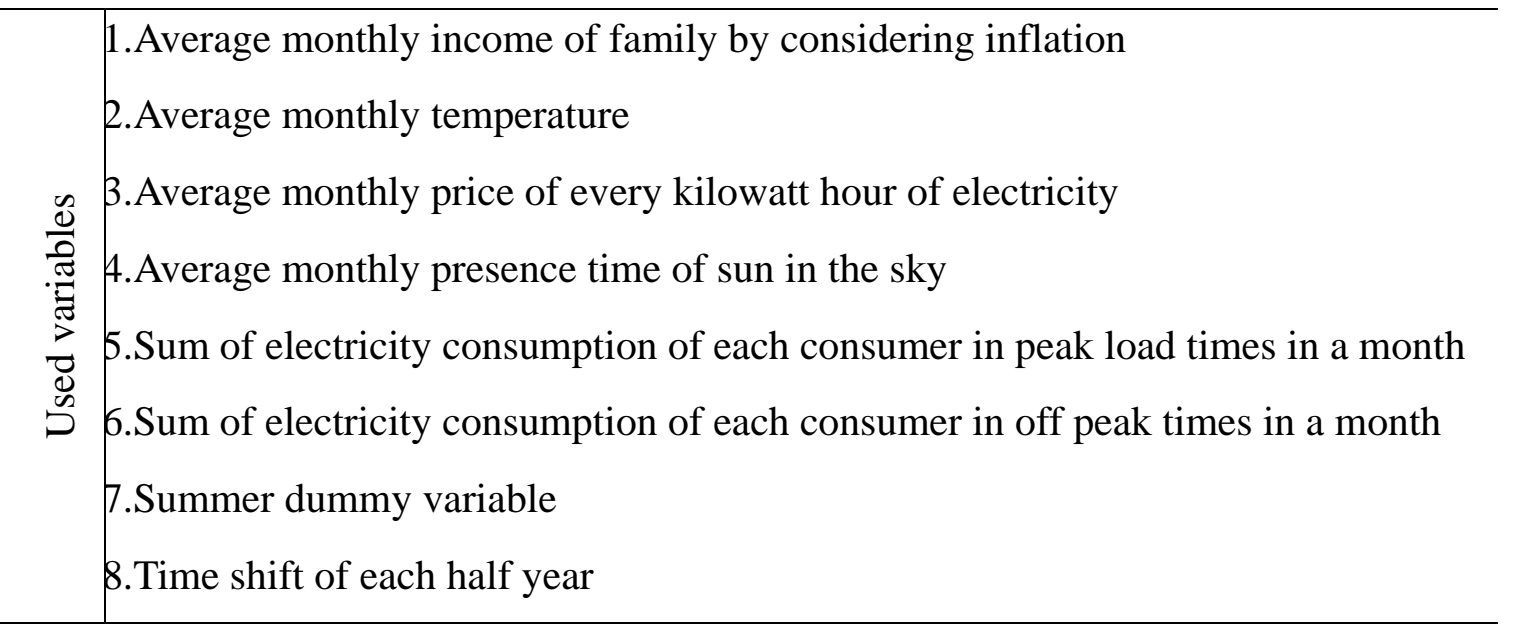

According to the table 2 there are two models for demands, one for peak load times and the other one for off peak times. (18) is the peak load times basic model of demand function and (19) is the off peak basic model of demand function. 


$$
\begin{aligned}
& Q_{\text {peakload }}=\text { Const }+\gamma_{1} \text { Price }_{\text {electricity }}+\gamma_{2} \text { Income }+\gamma_{3} T_{\text {mean }}+\gamma_{4} \text { Sunshine }+\gamma_{5} d_{\text {summer }} \\
& +\gamma_{6} d_{\text {Timeshift }} \\
& Q_{\text {offpeak }}=\text { Const }+\beta_{1} \text { Price } \text { electricity }+\beta_{2} \text { Income }+\beta_{3} T_{\text {mean }}+\beta_{4} \text { Sunshine }+\beta_{5} d_{\text {summer }} \\
& +\beta_{6} d_{\text {Timeshift }}
\end{aligned}
$$

\begin{tabular}{|c|c|}
\hline variables & Definition \\
\hline$Q_{\text {peakload }}$ & $\begin{array}{l}\text { Sum of electricity consumption of each consumer in peak load times in a } \\
\text { month in Tehran }\end{array}$ \\
\hline$Q_{\text {offpeak }}$ & $\begin{array}{l}\text { Sum of electricity consumption of each consumer in off peak times in a } \\
\text { month in Tehran }\end{array}$ \\
\hline Price $_{\text {electricity }}$ & $\begin{array}{l}\text { average monthly price of buying electricity from electricity market by the } \\
\text { Great Tehran electricity distribution company }\end{array}$ \\
\hline Income & Average monthly income of family by considering inflation \\
\hline$T_{\text {mean }}$ & Average monthly temperature of Tehran \\
\hline Sunshine & Average monthly presence time of sun in the sky in Tehran \\
\hline $\mathrm{d}_{\text {summer }}$ & dummy variable related to the three months of summer \\
\hline$d_{\text {Timeshift }}$ & dummy variable related to the time shift of each half year \\
\hline $\begin{array}{l}\gamma_{1}-\gamma_{6} \& \beta_{1} \\
-\beta_{6}\end{array}$ & Coefficients of the independent variables \\
\hline
\end{tabular}

Variable that are used in these models are described in Table 3.

Table 3: Definition of conceptual model of demand functions variables

\subsubsection{Third step or estimating demand functions}

In the third step with the help of SPSS software and regression analysis demand functions of peak load and off peak period are calculated. It must be noted that in SPSS software, backward regression model was used to estimate demand functions. (20) is the final estimated model of demand function in peak load and (21) is the final estimated model of demand function of off peak.

$$
\begin{gathered}
\mathrm{Q}_{\text {peakload }}=18.651-0.006 \text { Price }_{\text {electricity }}+0.13 \mathrm{~T}_{\text {mean }}+3.769 \mathrm{~d}_{\text {summer }} \\
\mathrm{Q}_{\text {offpeak }}=7.491-0.002 \text { Price }_{\text {electricity }}+0.107 \mathrm{~T}_{\text {mean }}+2.285 \mathrm{~d}_{\text {summer }}
\end{gathered}
$$

It must be considered that at the end of estimating demand functions there are 6 demand functions. 2 demand function for peak load and off peak periods of spring, 2 demand functions for peak load and off peak periods of summer and 2 demand functions for peak load and off peak periods of autumn and winter. In this study because of consumer behavior, 
demand functions of peak load and off peak times of spring, autumn and winter were the same. In Iran natural gas is used for heating houses in autumn and winter and electricity is rarely used for heating, then consumption behavior of spring is the same as autumn and winter. This reason can explain why electricity demands of spring, autumn and winter are the same. Also it must be noted that for determining peak load and off peak time demand functions of each season, average of temperature in the specified timing period of research was considered for $\mathrm{T}_{\text {mean }}$ and $d_{\text {summer }}$ has two inputs 1 for summer and 0 for other seasons. Average temperature is equal to $17.4^{\circ} \mathrm{C}$.

By the help of above explanation finally there are 4 demand functions for all the seasons in peak load and off peak periods. In the Table4 It is shown that what are the required inputs, in order to specify demand function of peak load and off peak times of each season.

Table 4: Required inputs for estimating electricity demand function of peak load and off peak times of each season

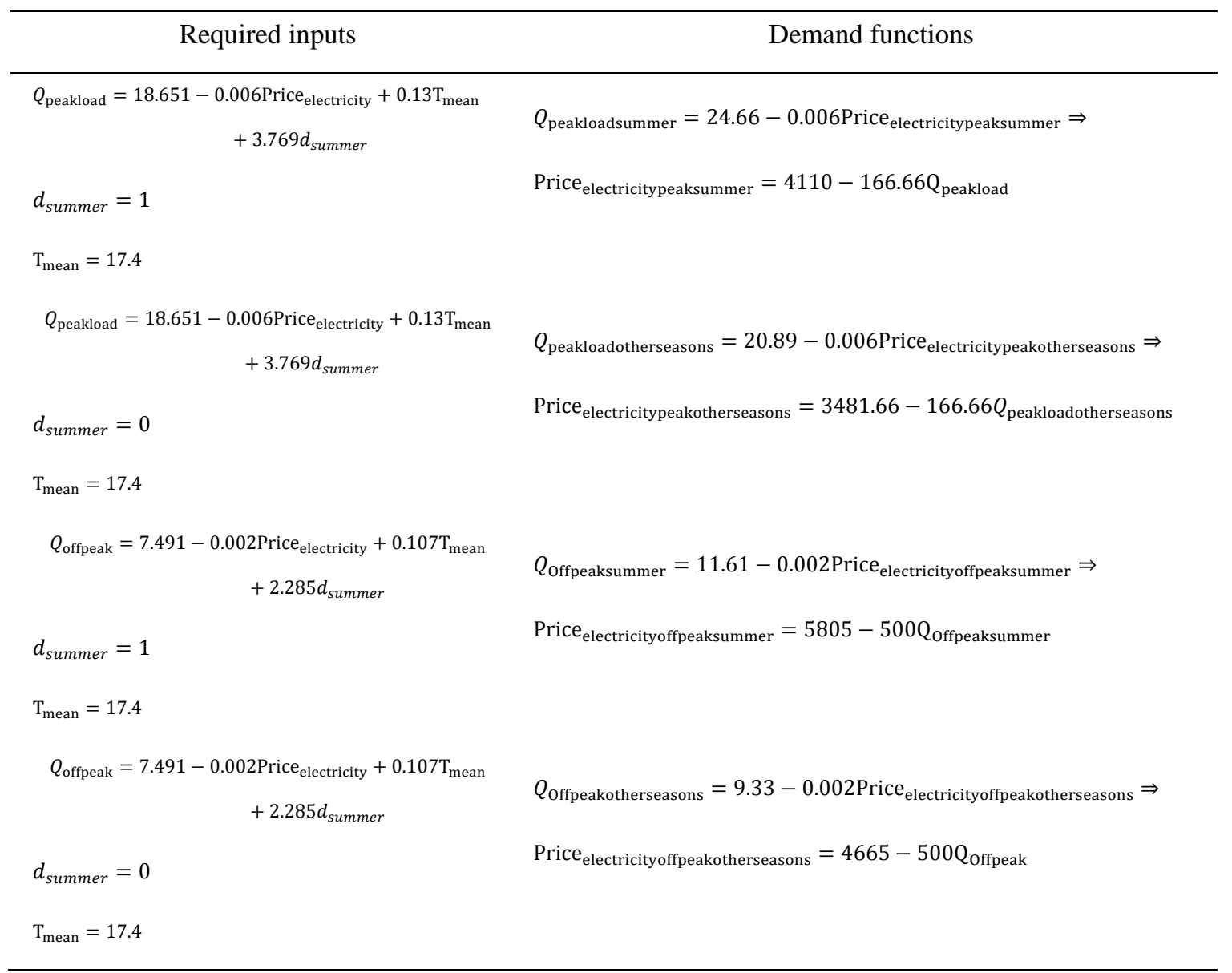

So (22) is the demand function of peak load in summer, (23) is the demand function of other three seasons, (24) is the demand function of off peak in summer and (25) is the demand function of off peak in other three seasons.

$Q_{\text {peakloadsummer }}=24.66-0.006$ Price electricitypeaksummer $\Rightarrow$ Price $_{\text {electricitypeaksummer }}=$

$4110-166.66 Q_{\text {peakloadsummer }}$ 


$$
\begin{aligned}
& \mathrm{Q}_{\text {peakloadotherseasons }}=20.89-0.006 \text { Price }_{\text {electricitypeakotherseasons }} \Rightarrow \\
& \text { Price } \\
& \mathrm{Q}_{\text {electricitypeakotherseasons }}=3481.66-166.66 \mathrm{Q}_{\text {peakloadotheseasons }} \\
& \text { Price }_{\text {electricityoffpeaksummer }}=5805-500 \mathrm{Q}_{\text {Offpeaksummer }} \\
& \mathrm{Q}_{\text {Offpeakotherseasons }}=9.33-0.002 \text { Price } \\
& \text { Price }_{\text {electricityoffpeakotherseasons }} \Rightarrow
\end{aligned}
$$

It should be noted that in household electricity consumption of Tehran, consumers uses more electricity in summer for running cooling systems and in this season distribution company faces more demand for electricity. In other seasons there is a nearly fixed pattern for electricity consumption and because of this demand functions of spring, autumn and winter are the same.

\subsubsection{Forth step or determining operational and capacity costs}

After estimating demand functions it is recommended to find or calculate generation, transmission and distribution costs of electricity, in order to calculate suitable prices for electricity. For using the peak load pricing method it is necessary to find or calculate two types of costs. These costs are operational cost of each kilowatt hour of electricity that is shown by $\mu_{0}$ and capacity cost of each kilo watt hour of electricity that is shown by $\mu_{k}$.

Great Tehran Distribution Company buys electricity from electricity market and sells it to the consumers. Therefore it isn't necessary to calculate generation, transmission and distribution costs to find the operational cost of each kilo watt hour of electricity. Hence average buying price of electricity from the market was used as operational cost. So on average operational costs of each kilowatt hour of electricity for the year 1391 (2012-2013) according to the electricity that was bought from the electricity market in Distribution Company is equal to 500 Rials. Because there are subsidies in Iran's electricity industry it is not possible to use real and exact capacity costs for calculating electricity sell price for household consumers. Because if disregard costs of transmission and distribution networks and capacity cost assumed to be cost of constructing a power planet then cost of increasing capacity per each kilowatt hour is 5500000 Rials(Note 1) if a 2000 MW is constructed (S. Kamalinia,M. Shahidehpour, 2009). There is subsides in Iran's electricity industry and because of that it is not possible to use 220 dollars for capacity costs because this cost will not cut demand functions. So in this study it was assumed that capacity costs for each kilowatt hour is equal to operational cost of each kilowatt hour that is nearly 500 Rials

\subsubsection{Final step or calculating electricity prices for seasons}

In this step prices for public utility service provider and private sector in each season are calculated.

\subsubsection{Calculating Public utility service provider prices}

It must be noted that still structure of electricity network of Iran is governmental and isn't 
completely assigned to the private sector. So it is assumed that Tehran Distribution Company that is front line and is connected to final consumer is a public utility service provider. Hence for electricity pricing in this method as is shown in (25) it is necessary for Distribution Company to only cover its costs with its incomes. As regards, electricity costs that are used in this study are for the years between 2011 to 2013 then marginal cost is equal to average cost and it is shown in (26).also this method of pricing can be used for pricing in private sector. For pricing in private sector marginal revenue must be equal to marginal cost to cover all costs and have profit for the company.

$$
\begin{aligned}
\mathrm{P} & =\mathrm{MC} \\
\mathrm{MC} & =\mathrm{AC}
\end{aligned}
$$

For calculating electricity prices with the help of peak load pricing method for public utility service provider it must be assumed that one of the periods is peak load period and other period is off peak. It must be noted that this calculation must be done for each season separately. Hence for summer calculation is described below.

According to (27) at first for public utility service provider amount of electricity consumption is calculated and after that according to (28) amount of electricity consumption for off peak period is estimated. If electricity consumption that was calculated for peak load period is more that electricity consumption of off peak period then it means that peak load period was chosen correctly and sum of operational and capacity cost should be considered as price of this period. Electricity price of off peak period should be equal to operational costs. If amount of electricity consumption of off peak period in this situation is more than electricity consumption of peak load period then it must be assumed that other period is peak load and amount of electricity consumption for this situation must be calculated. Other condition such as shifting peak and so on is possible that this method can solve them and find a good price for the services or products.

$$
\begin{aligned}
& \text { Price }_{\text {electricity }}^{\prime}=20 * \text { Price }_{\text {electricityoffpeaksummer }}=20 *\left(5805-500 Q_{\text {Offpeaksummer }}\right)= \\
& 20 * \mu_{\mathrm{o}}=20 * 500 \Rightarrow \mathrm{Q}_{\text {Offpeak }}=10.61 \\
& \text { Price }_{\text {electricity }}^{\prime \prime} 4 * \text { Price }_{\text {electricity }}=4 *\left(4110-166.66 Q_{\text {peakload }}\right)=\mu_{\mathrm{k}}+4 * \mu_{\mathrm{k}}=2500 \Rightarrow \\
& Q_{\text {peakload }}=20.91
\end{aligned}
$$

As it is shown in (11) and (12) numbers of hours of each time period are multiplied and that's because the demand function was estimated for each hour and each time period of peak load and off peak is consist of several hours. According to the definition of Tehran Distribution Company peak load times are 4 hours and other 20 hours are off peak.

Calculations of other season's price for public utility service provider are shown in (29) and (30). Comments about this part are the same as paragraph above.

$$
\begin{aligned}
& \text { Price }_{\text {electricity }}^{\prime \prime \prime}=20 * \text { Price }_{\text {electricityoffpeakotherseasons }}= \\
& 20 *\left(4665-500 Q_{\text {offpeakotherseasons }}\right)=20 * \mu_{\mathrm{o}}=20 * 500 \Rightarrow \text { Q }_{\text {Offpeakotherseasons }}=
\end{aligned}
$$




\subsection{3}

Price $_{\text {electricity }}^{\prime \prime \prime}=4 *$ Price $_{\text {electricitypeakloadotherseasons }}=$

$4 *\left(3481.66-166.66 Q_{\text {peakloadotherseasons }}\right)=\mu_{\mathrm{k}}+4 * \mu_{\mathrm{k}}=2500 \Rightarrow$

$\mathrm{Q}_{\text {peakloadotherseasons }}=17.14$

Results of calculations for a public utility service provider shows that according to the costs of Distribution Company in current situation it is suitable to choose 1000 Rials for each kWh in peak load period as the price and for off peak periods choose 500 Rials for each $\mathrm{kWh}$ as the price. Also it must be noted that this model can calculate prices for all season separately for peak load and off peak period of each season but in this study due to the lack of data about costs of electricity Distribution Company, researchers had to use average cost of buying electricity from electricity market for peak load and off peak period s of all seasons.

\subsubsection{Calculating private sector prices}

It must be noted that according to (31) it is possible to calculate electricity price for the times that Distribution Company is assigned to private sector. According to the cost structure and demand functions of current situation calculation of prices were not acceptable. This shows that Existence subsides is a reason that calculations lead to inappropriate prices and shows why investing in electricity industry is not interesting for private sector.

$$
\mathrm{MR}=\mathrm{MC}
$$

According to the above description results of electricity pricing for private sector is shown below. For calculating electricity price for private sector it is necessary to calculate marginal revenue from inverse demand function and then calculating electricity price for peak load and off peak of each season. For calculating marginal revenue this method must be considered. If $P=\alpha-\beta q$ then

$$
\operatorname{MR}(q) \frac{d x(q)}{d q}=\frac{d[p(q) q]}{d q}=\alpha-2 \beta q
$$

Marginal revenues of demand functions are shown in table5.

\begin{tabular}{|c|c|}
\hline Demand functions & Marginal revenue \\
\hline $\begin{array}{l}\text { Qpeakloadsummer } \\
\qquad \begin{aligned} & \\
& \\
& -0.006 \text { Price } \\
& \Rightarrow\end{aligned}\end{array}$ & $\begin{array}{l}\text { MR }_{\text {peakloadsummer }} \\
=4110-333.32 Q_{\text {peakloadsummer }}\end{array}$ \\
\hline $\begin{array}{l}\text { Price }_{\text {electricitypeaksummer }} \\
\qquad=4110-166.66 Q_{\text {peakload }}\end{array}$ & \\
\hline
\end{tabular}

Table 5: Marginal revenues 


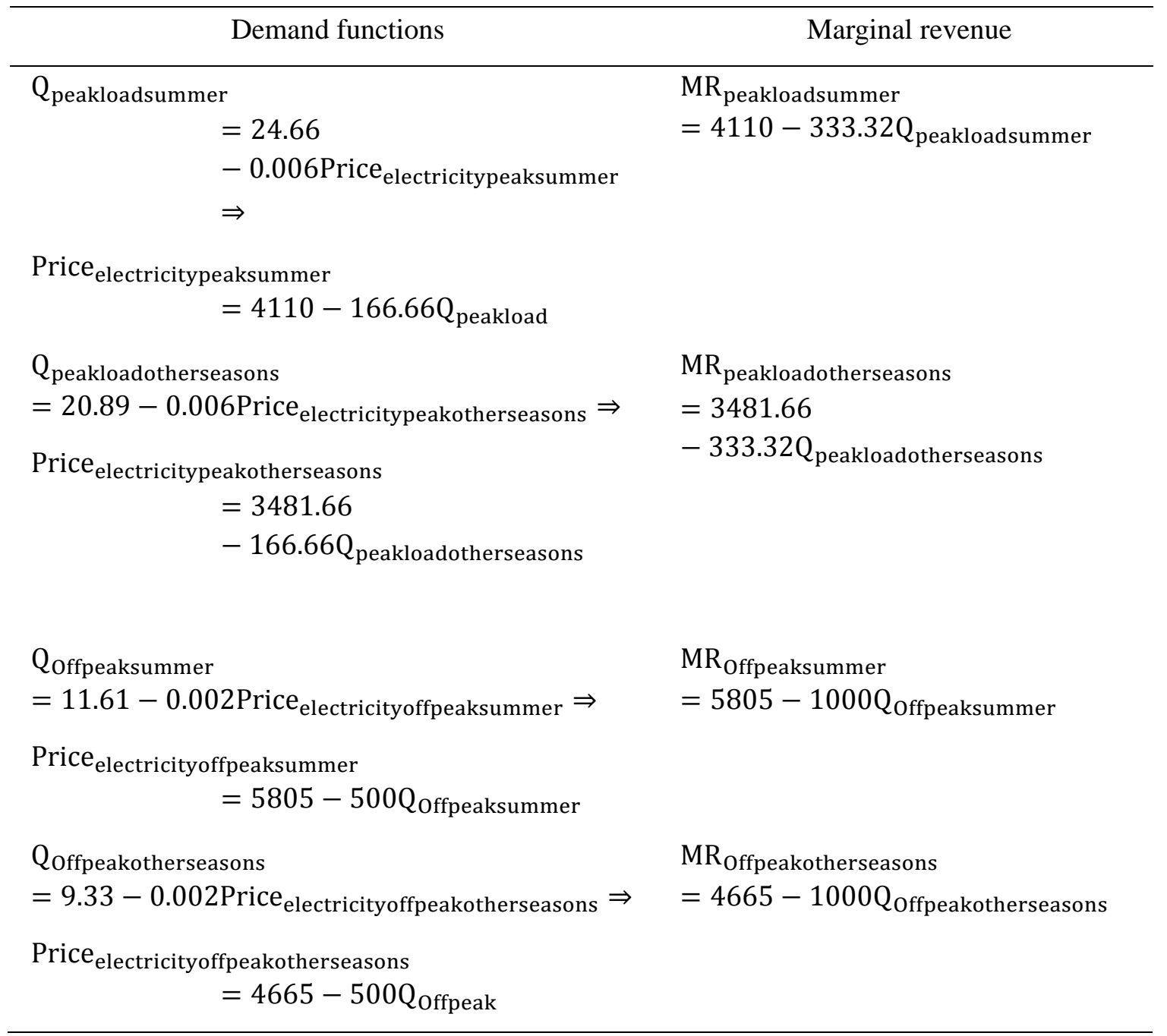

All the process of calculating the prices is the same as peak load pricing method for public utility service provider but there are to differences. At first for marginal revenue functions are used instead of demand functions and other difference is that after estimating the $Q_{\text {offpeak }} \&$ $\mathrm{Q}_{\text {peakload }}$ and finding the correct peak load period, $\mathrm{Q}_{\text {offpeak }} \& \mathrm{Q}_{\text {peakload }}$ are inserted in to the demand functions to calculate appropriate price for each period of each season.

$$
\begin{aligned}
& 20 * \mathrm{MR}_{\text {Offpeaksummer }}=20 *\left(5805-1000 \mathrm{Q}_{\text {Offpeaksummer }}\right)=20 * \mu_{\mathrm{o}}=20 * 500 \Rightarrow \\
& \mathrm{Q}_{\text {Offpeaksummer }}=5.3 \\
& \mathrm{Q}_{\text {Offpeaksummer }}=5.3 \& \text { Price }_{\text {electricityoffpeaksummer }}=5805-500 \mathrm{Q}_{\text {Offpeaksummer }} \Rightarrow \\
& \text { Price }_{\text {electricityoffpeaksummer }}=3155
\end{aligned}
$$

$4 * \mathrm{MR}_{\text {peakloadsummer }}=4 *\left(4110-333.32 \mathrm{Q}_{\text {peakloadsummer }}\right)=\mu_{\mathrm{k}}+4 * \mu_{\mathrm{k}}=2500 \Rightarrow$ 
$\mathrm{Q}_{\text {peakloadsummer }}=10.45$

$\mathrm{Q}_{\text {peakloadsummer }}=10.45 \&$ Price electricitypeakloadsummer $=$

$4110-166.66 Q_{\text {peakloadsummer }} \Rightarrow$ Price $_{\text {electricitypeakloadsummer }}=2368$

$20 * \mathrm{MR}_{\text {Offpeakotherseasons }}=20 *\left(4665-1000 Q_{\text {Offpeakotherseasons }}\right)=20 * \mu_{\mathrm{o}}=20 *$

$500 \Rightarrow Q_{\text {Offpeakotherseasons }}=4.165$

$\mathrm{Q}_{\text {Offpeakotherseasons }}=4.165 \&$ Price $_{\text {electricityoffpeakotherseasons }}=$

$4665-500 Q_{\text {offpeakotherseasons }} \Rightarrow$ Price $_{\text {electricityoffpeakotherseasons }}=2582$

$4 * \mathrm{MR}_{\text {peakloadotherseasons }}=4 *\left(3481.66-333.32 \mathrm{Q}_{\text {peakloadotherseasons }}\right)=\mu_{\mathrm{k}}+4 * \mu_{\mathrm{k}}=$

$2500 \Rightarrow Q_{\text {peakloadotherseasons }}=8.57$

$\mathrm{Q}_{\text {peakloadotherseasons }}=8.57 \&$ Price electricitypeakotherseasons $=$

$3481.66-166.66 Q_{\text {peakloadotherseasons }} \Rightarrow$ Price $_{\text {electricitypeakotherseasons }}=2053$

As it was mentioned before because governmental structure of Iran's electricity industry and existence of subsides private sector solution doesn't have appropriate results for prices because existence of subsides biases demand functions and amount of electricity consumption. This can prove that why Iran's electricity industry must still stay governmental and why private sector doesn't show interest to invest in this market.

\section{Conclusions}

Electricity is introduced as a commodity that is given to the applicants or consumers as a service. There is an important point about electricity, it must be known that electricity is not storable and immediately after generation must be consumed otherwise it is wasted. According to replacing analog power meters with digital power meter multi-tariff, it is necessary to calculate electricity price for each period of time.

Electricity as a service has a particular life cycle that in this life cycle generation, transmission and distribution exists. In each of these steps it is possible to have private firms or governmental firms and it must be noted that for each step of this life cycle next step act as customer. So it is suggested to calculate price for each step. In this study it was tried to offer prices for electricity according to customers' behavior.

In this study it was tried to calculate suitable prices in peak load and off peak periods for a 
public utility service provider with the help of estimated demand functions. But due to the limitation in accessing costs data of great Tehran Distribution Company and existence of subsides in electricity industry, estimated prices cannot be according to real costs. For example to construct a new $2000 \mathrm{MW}$ power planet for each KW electricity it is necessary to invest more than 220 dollars. If this cost is used as the capacity cost regardless of transmission and distribution costs for calculating the prices, cost functions will cut demand functions in a region that the answer is not acceptable. It is possible to calculate better prices when real costs of generation, transmission and distribution are included and subsides are eliminated. Also results shows that at the present time in the current situation private sector solution doesn't have appropriate results then it is suggested that this industry still be governmental and the government with the help of productivity solution and managements keeps electricity generation at the level of the breakeven. Because there is a big distance between amount of electricity consumption at the level of the breakeven and electricity consumption of off peak period. It is suggested that government adopt strategies that helps to reduce peak load time's electricity consumption. It is suggested to use non-linear demand function instead of linear demand function in future studies.

\section{References}

Coslovich, L. (2008). A model for setting and validating sale prices of an electricity trader by means of load shifts. Journal of Energy, emerald, 2, 351-367. http://dx.doi.org/10.1108/17506220810892928

Ekhlasi, A. (2011). Marketing principle (first ed.). Tehran: elmi pub.

Ekhlasi, A. (2011). Service marketing (First ed.). Tehran: elmi pub.

GR Newsham, \& BG Bowker. (2010). The effect of utility time-varying pricing and load control strategies on residential summer peak electricity use: A review. Energy Policy, 38(7), 3289-3296. http://dx.doi.org/10.1016/j.enpol.2010.01.027

Herter, K. (2007). Residential implementation of critical peak pricing of electricity. Energy Policy, 35(4), 2121-2130. http://dx.doi.org/10.1016/j.enpol.2006.06.019

J. Pazhohan, \& T. Mohammadi. (2001). Ramsey optimal Pricing for the electricity industry in Iran. Iranian journal of Economic Research, 6, 144.

Jeff Tanner \& Mary Anne Raymond. (2010). Principles of Marketing. Flat World Knowledge.

Karen Herter \& Seth Wayland. (2010). Residential response to critical-peak pricing of electricity: California evidence. Energy policy, 35(4), 1561-1567. http://dx.doi.org /10.1016/j.energy.2009.07.022

S. Kamalinia, \& M. Shahidehpour. (2009). Capacity adequacy calculation by considering locational capacity prices. IET Generation, Transmission \& Distribution, 4(3), 376-385. http://dx.doi.org/10.1049/iet-gtd.2009.0319 
Shy, o. (2008). How to price. Cambridge University Press.

Vilhelm Horn af Rantzien, Anna Syrén. (2010). peak load pricing in public transport: a case study of Stockholm. STOCKHOLM: STOCKHOLM SCHOOL OF ECONOMICS.

\section{Note}

Note 1. 220 dollars in the condition that every dollar equals 25000 Rials

\section{Copyright Disclaimer}

Copyright reserved by the author(s).

This article is an open-access article distributed under the terms and conditions of the Creative Commons Attribution license (http://creativecommons.org/licenses/by/3.0/). 